\title{
Joyce Carol Oates Traduz um Autor Português: Ela Própria
}

Mário Bruno Cruz

(CETAPS)

o presente artigo iremos analisar duas importantes narrativas de The Poisoned Kiss and Other Stories From the Portuguese (1975) de Joyce Carol Oates, "Letters to Fernandes from a Young American Poet" e "Plagiarized Material", para compreender como Portugal foi utilizado como pretexto para Oates marcar uma posição no meio literário norte-americano da época. E, por outro lado, como a apropriação (ao estilo pessoano?) do pseudónimo Fernandes de Briao terá permitido a Oates libertar uma faceta porventura mais recalcada e, desse modo, enriquecer a sua persona artística.

Em inícios dos anos setenta, no princípio da retirada das tropas na Guerra do Vietname, o movimento hippie culminava no Festival de Woodstock (Agosto 1969), desacreditava-se no sistema político norte-americano e as filosofias orientais, como o Budismo e o Hinduísmo, tornavam-se moda nos Estados Unidos. Joyce Carol Oates (n. 1938), ainda no princípio da sua vida literária, tendo publicado apenas cerca de uma dúzia de livros (contando hoje com quase duas centenas), escreveu, em Novembro 1970, a obra em que se relaciona com Portugal. Publicada nos Estados Unidos, um ano após a Revolução dos Cravos, em 1975, a colectânea contém uma série de contos, 
muitos deles já anteriormente vindos a lume em diversas publicações periódicas, assinados como traduções do português por Joyce Carol Oates. A autoria é dividida, conforme se constata na capa e, depois, no Prefácio, entre a tradutora, Joyce Carol Oates e Fernandes de Briao, o alegado autor português. George Monteiro, em "Imaginary Poets in Real World (an Unpublished Lecture, 1996)" (302-303), citando Fernando Pessoa (1888-1935), refere que "a pseudonymic work is, except for the name with which it is signed, the work of an author writing as himself; a heteronymic work is by an author writing outside his own personality: it is the work of a complete individuality made up by him, just as the utterances of some character in a drama would be." (Presença, n. ${ }^{\circ}$ 17, 1928: 10)

Sem o reconhecer, Oates assume um pseudónimo literário que permitirá posicionar-se no contexto da literatura norte-americana, sem se expor directamente. É caso para perguntar se, em começo de carreira, Oates terá querido proteger-se. Por outro lado, esse posicionamento sob a forma de um exercício literário, praticado aquando da escrita de outra obra (Wonderland, 1971), ter-lhe-á permitido clarificar ideias e separar as águas. Trata-se de um exercício literário quase teórico, mas que a poderia ter ajudado a redigir Wonderland, obra escrita em simultâneo com The Poisoned Kiss and Other Stories From the Portuguese, e a marcar uma posição no mundo da escrita norteamericana. Deve notar-se notar que, para Pessoa, os heterónimos são personas literárias completamente autónomas que "não representam [as suas] opiniões ou emoções", (Pessoa apud Monteiro 2016, 303) sendo que o uso de um pseudónimo, ainda segundo o poeta, já lhe permitiria expressar os seus próprios pontos de vista. Daí a opção de Oates por um pseudónimo e não por um heterónimo.

Nesta colectânea, as referências a Portugal são meras alusões, por vezes distantes, mais parecendo o tema ser a América profunda, como em "Parricide", onde se aparenta mais descrever um crime de um psicopata norte-americano do que de um criminoso português da época. Talvez a arma do crime fosse outra em ambiente luso, em vez de um machado quiçá uma enxada. Em relação ao conto "The Brain of Dr. Vicente", Oates parece referir-se vagamente a alguma 
história relacionada com o Professor Egas Moniz, embora a lobotomia também tivesse sido bastante popular nos Estados Unidos. No entanto, se se atentar no conto, "Letters to Fernandes from a Young American Poet", verifica-se que abundam as referências políticas ao regime de Salazar (embora os contos já tenham sido escritos durante o Marcelismo) que Oates utilizará como metáfora extrema da situação nos Estados Unidos ou talvez do que os Estados Unidos poderiam vir a ser. Tal reafirma a ideia de que a obra constituiu um exercício teórico, uma paragem para a reflexão, e não propriamente um livro sobre Portugal. "Portugal" poderá ter sido apenas mais um "pseudónimo" utilizado, em vez de "Estados Unidos", uma forma de falar acerca deste último país, sem o referir directamente. Podemos até perguntarmo-nos se o "beijo envenenado" não virá do próprio país de Oates, com uma literatura considerada decadente que ela pretende suplantar, reflexo quiçá do beco sem saída político em que os Estados Unidos se encontravam. (McCarthy, "The Vassar Girl", 1933-1974)1

Se se comparar com a visão de Mary McCarthy (1912-1989) sobre Salazar, ${ }^{2}$ - "We were expecting an idyll and apprehending a dictatorship. These two notions had fused, for the time being, in a resolve not to be insular: democracy was not necessarily suited to all countries, we assured each other, gripping our travel books. 'Salazar is a very good man, very wise for is people,' said an old Portuguese-American (...)" (McCarthy 1951, 106) - com a de Joyce Carol Oates - "Dr. S, who has done 'so much a foreigner can't understand (...)'" $(1975,141)-\mathrm{e}$, depois, com tudo o que se lê em "Letters to Fernandes from a Young American Poet", esta última acaba por ser muito mais crítica e, talvez, conhecedora da realidade política portuguesa de época, embora nunca tivesse estado em Portugal, ao contrário de Mary McCarthy. Tal visão revela que, apesar de tudo, Oates teria alguma curiosidade pela realidade do nosso país e que, apesar de utilizar o nome de Portugal para marcar uma posição nos Estados Unidos, poderá ter sentido alguma vontade de escrever sobre Portugal. Curiosidade pelo nosso

1. https://www.youtube.com/watch? $\mathrm{v}=-\mathrm{rIMKDx} 94 \mathrm{OU} \& \mathrm{t}=1006 \mathrm{~s}$

2. Cf. Cruz 2016: 383-401. 
país, vinda talvez da leitura de Roy Campbell (1901-1957) e Thomas Merton (1915-1968), que se aludirá mais adiante.

No primeiro conto, as referências a Portugal surgem de um modo algo confuso. Aqui refere-se a localidade portuguesa de Alferce, uma vila na serra algarvia, perto de Monchique, onde o ambiente de devoção a $\mathrm{N}^{\text {a }} \mathrm{S}^{\mathrm{a}}$ de Fátima provavelmente não seria tão intenso como o descrito, parecendo o ambiente retratado neste conto mais próprio de uma vila mais a Norte, onde a devoção religiosa se mostraria com maior intensidade do que no Algarve, embora se deva sempre ter em conta que a acção narrativa corresponde a uma época em que o povo português se encontrava mais voltado para a prática da religião. O conto que confere o título ao livro, "The Poisoned Kiss", é quase um não-conto (pois praticamente não há enredo), tendo de Portugal apenas o facto de a acção se desenrolar nuns claustros (de um convento?). Aparentemente trata-se do conto com o título com mais força expressiva e maior significado metafórico, conferindo, assim o título à obra. As denominações dos restantes contos afiguram-se menos expressivas, possuindo menor carga semântica. Portugal surge retratado de forma algo nublosa. Tal revela alguma falta de acesso a informação sobre o país, por parte de Oates, apesar de, como veremos a seguir, a obra de Campbell a poder ter esclarecido, visto este autor, citado na epígrafe da obra de Oates, ter escrito acerca do nosso país e ter cá vivido pelo menos durante seis anos.

Carol Oates escolheu, para epígrafe desta obra, uma citação de um poeta espanhol (San Juan de la Cruz), numa tradução de 1960 de Campbell, um poeta sul-africano que viveu e escreveu sobre Portugal. Ao contrário de Oates, que, se não critica claramente Salazar, pelo menos expõe abertamente as arbitrariedades do regime, Campbell, nascido em Durban, como Pessoa, era um admirador de Salazar e um devoto de $\mathrm{N}^{\text {a }} \mathrm{S}^{\text {a }}$ de Fátima. Campbell viveu em Portugal em 1937 e entre 1952 e 1957, deixou um estudo incompleto intitulado "Fernando Pessoa" (Monteiro 2010, 135) e um livro sobre Portugal, 
vindo a falecer em 1957, perto de Setúbal. ${ }^{3}$ Esta contradição poderá ser reveladora da dificuldade de acesso, nessa época, a informação literária e política em inglês acerca do nosso país, tendo Oates que se sujeitar a informação vinda de quem teria posições políticas opostas às suas.

Uma questão que se levanta logo à partida é a pertinência da epígrafe, que, aparentemente, reforça aquilo que Oates poderá pretender com The Poisoned Kiss and Other Stories From the Portuguese. Carol Oates (a amada) com este exercício de escrita transformar-se-á num português (o amado), num filho de Fernando Pessoa. Como acertadamente João Paulo Moreira (9) refere e Susana Araújo (66) reafirma, citando-o, Fernandes, em português, significou, na época de Gil Vicente, filho de Fernando. Oates poderá de facto ter lido a obra de Campbell relativa a Pessoa. Poder-se-ia defender que seria mais adequado citar, por exemplo, Camões, poeta admirado por Campbell, mas que nunca traduziu, (Monteiro 1998, 23) do que um poeta espanhol num livro supostamente português:

Transforma-se o amador na cousa amada.

por virtude do que muito imaginar;

não tenho, logo, mais do que desejar,

pois em mim tenho a parte desejada. $(2005,20)$

Em lugar de:

(...) Oh noche, que guiaste,

Oh noche amable más que el alborada:

Oh noche, que juntaste

Amado con amada,

Amada en el Amado transformada! $(1975,7)$

3. Sobre a importância de Roy Campbell para as relações luso-britânicas, veja-se Miguel Alarcão, "Roy Campbell (1901-1957): o Hispanista Escocês da África Austral". REAP, $\mathrm{n}^{\circ} 16$ (2007): 135-159 e também Maria do Rosário Lupi Bello e Miguel Alarcão, "Roy Campbell (1901-1957): The Life, Times and Opinions of a South African 'Cowboer'". REAP, $\mathrm{n}^{\circ} 22$ (2013): 209-223. 
No entanto, no excerto escolhido por Oates, o elemento "noite" poderá representar a noite do fascismo português e a noite da decadência literária nos Estados Unidos, que "juntou" Oates a Portugal e a Pessoa, transformando-se a primeira no segundo, a amada no amado. Pessoa surge como um um poeta "santificador" e não como um artista atolado no pântano da consciência, como referiremos mais adiante.

À luz do que se reflectiu até aqui, parece muito provável que Oates tenha lido Pessoa antes da escrita desta obra. Será que o terá lido na tradução de doze poemas de O Guardador de Rebanhos de Alberto Caeiro realizada por Thomas Merton, em 1965, e publicada na revista literária de Nova Iorque, New Directions? Terá sido por o conhecer através da tradução de Merton, onde Alberto Caeiro lhe terá surgido aparentemente próximo do budismo, apresentando interrogações um tanto ou quanto semelhantes às que Oates revela no posfácio, quando afirma: "one cannot know, really, what the 'self' is". Terá Oates procurado conhecer o nosso poeta? A própria Joyce Carol Oates nunca reconheceu qualquer influência de Pessoa $^{4}$ na sua escrita. Segundo James R. Giles,

Ultimately, Oates was "besieged" [sic] to "translate" Fernandes' visions into the twenty three [sic] "parables" contained in The Poisoned Kiss: "I was never able to designate myself as the author of the stories; they were all published under the name 'Fernandes' and I was listed as having translated them 'from the Portuguese." It is not my concern to speculate upon this experience of "real or imagined 'possession'" in itself. There is no reason to doubt Oates' statement that whatever she felt was intense enough to result in extensive investigation into "parapsychology, mysticism, the occult and related subjects". (138)

Tal como Oates, Pesssoa também terá sido possuído pelos seus heterónimos:

4. Cf. Monteiro 1998, X e 11; e Monteiro 2016, 299. 
(...) on March 8, 1914 - I found myself standing before a tall chest of drawers, took up a piece of paper, began to write, remaining upright all the while since I always stand when I can. I wrote thirty some poems in a row, all in a kind of ecstasy, the nature of which I shall never fathom. It was the triumphant day of my life, and I shall never have another like it. I began with a title, The Keeper of Sheep. And what followed was the appearance of someone within me to whom I promptly assigned the name of Alberto Caeiro. Please excuse the absurdity of what I am about to say, but there had appeared within me, then and there, my own master. (Pessoa apud Monteiro 2016, 301)

Também Pessoa com os seus heterónimos entra numa espécie de êxtase libertador e conhece o seu próprio Mestre, Alberto Caeiro. Devemos interrogarmo-nos se Fernandes de Briao, um possível Fernando Pessoa, como aventámos, não será, de certo modo, também o Mestre de Oates. Ora, tal remete para outro campo, mais pessoano e menos budista (ou talvez não), se bem que, como se referiu, as interrogações sobre o que é o "eu" e sobre se o cérebro contém a mente ou se gera a mente, transportem para o que alguns cientistas associados ao Mind and Life Institute actualmente se encontram a reflectir, com base no estudo da ciência da mente budista. ${ }^{5}$

No seu artigo acerca da obra em análise, Giles defende que Oates pretendeu "salvar" o leitor do caos do mundo através da sua recriação. Para isso, o artista deverá incorporar o "santo" e o "demónio" e traduzi-los na linguagem humana, criando visões estéticas "santificadas" e levando (ao contrário do que defendiam muitos intelectuais cépticos da época) a literatura a assumir um papel transformador. Esses autores cépticos, como William S. Burroughs (1914-1997) e Thomas Pynchon (n. 1937), entre outros, que Oates considera terem perdido a fé nas suas próprias "personalidades", não poderão desempenhar o "papel sagrado" do artista redentor. ${ }^{6}$ Este conjunto de contos terá

5. Cf. Ricard e Singer, 2017. Vejam-se também as reflexões do filósofo David Chalmers.

6. Cf. Giles 1979, 140. 
também representado para Oates uma forma de libertar a parte da sua personalidade que fora abafada:

the only way I could accept these stories [Fernandes' 'parables'] was to think of them as a literary adventure, or a cerebral/Gothic commentary on my own writing, or as the expression of a part of my personality that had been stifled. (Apud Giles 1979, 140)

Trata-se, como foi atrás referido, de algo escrito no decurso da elaboração de outra obra sua, Wonderland, talvez como forma de incorporar o "demónio", a parte mais oculta da sua personalidade, e poder, assim, desempenhar o referido "papel sagrado" do artista redentor. E fê-lo através da escolha de uma "world-view quite antithetical to my own", (Oates 1975, 15) oriunda de um "Portugal" mítico que, neste caso, poderia ser o mesmo a que um português se refere quando evoca a histórias das arábias ou da China, ou seja, algo distante, misterioso, desconhecido e exótico. Deste modo, Oates procurara no Portugal da ditadura fascista, o lado "demoníaco"/obscuro de uma norte-americana dos anos sessenta, ela própria. No seu artigo sobre esta obra, Olson Padgett afirma o seguinte: "When Joyce Carol Oates looks at Portugal, she sees herself." $(1994,678)$ De facto, Oates parece utilizar Portugal para se conhecer a si mesma: "Contact with the other allows a vital moment of recognition, which is as psychological as ideological. It is this connection that fuels Oates's project in the Poisoned Kiss." (Araújo 2010, 23) Deve notar-se que o Portugal dos anos sessenta, que se encontrava de candeias às avessas com os Estado Unidos, ao nível das relações internacionais, ${ }^{7}$ causava provavelmente uma impressão soturna numa escritora norte-americana da época, Joyce Carol Oates. Tratava-se de uma imagem de um país obscuro e distante. Neste contexto, a elaboração de The Poisoned Kiss and Other Stories From the Portuguese teria constituído um escape para a sua habitual tarefa de escrita e contrabalançado a composição de Wonderland/País das Maravilhas. Imaginar e "construir" um país

7. Cf. Terenas 2008, 287-301. 
desconhecido libertou-a para uma escrita "mais séria" e, ao mesmo tempo, reequilibrou-a, deixando-a assumir o seu lado "abafado", mais oculto e "demoníaco", isto porque Oates acreditava na completude da "personalidade". (Giles 1979, 141) Segundo Giles, apesar de se deixar fascinar, a sociedade respeitável procurava reprimir tudo o que acreditava ser "não-natural", e Oates, na obra em análise, examina quatro variações específicas de tal repressão: a científica, a parental, a governamental e a religiosa. Giles afirma, ainda, que o cenário português permite a Oates utilizar o fascismo como metáfora da democracia corrupta norte-americana. Curiosamente, o advento da revolução dos cravos em Portugal não demove Oates de editar o livro, publicando-o um ano após a alteração de regime em Portugal, o que, de certa forma, terá desactualizado a obra.

Como se referiu atrás, em 1970, Oates deparou-se com uma série de escritores norte-americanos pós-modernos, cépticos, que se encontravam "permanentemente atolados no pântano da consciência", (Oates 1975, 143) como descreve Giles, citando Tony Tanner, e num obsessivo experimentalismo de linguagem resultante de uma perda de confiança na sua viabilidade como forma de comunicação com sentido, sendo Jorge Luis Borges (1899-1986) e Vladimir Nabokov (1899-1977) as duas grandes fontes de inspiração para estes cépticos. Ora, o conto, "Letters from Fernandes from a Young American Poet" constitui precisamente uma parábola do exercício que Oates realizou com The Poisoned Kiss and Other Stories From the Portuguese. Também neste conto, um escritor norte-americano traduz um autor português (aí referido como António ou "A"). Tal feito permitiu-lhe prosseguir o seu percurso literário por entre o "pântano da consciência" onde se encontravam atolados muitos outros colegas escritores norte-americanos. O jovem poeta norte-americano teria aprendido a língua portuguesa para traduzir para inglês o misterioso poeta luso António ou "A", descoberto numa revista italiana. Poderia " $\mathrm{A}$ " referir-se a Pessoa? "A" era um admirador de Walt Whitman (1819-1892) e curiosamente Borges afirma o seguinte sobre Pessoa: "Fue equiparado a Walt Whitman, mereció el epíteto de genial e hizo sentir su influencia en ambas costas del Atlántico." (Apud Ferrari e Pizarro 2008, 91) 
Recorde-se que "A" ou António surge no segundo nome de Fernando Pessoa, cujo nome completo é Fernando António Nogueira Pessoa. A tradução (de 1965) do livro de poemas de "A", The Sheated Son of God (O Despojado Filho de Deus - O Cristo) terá sido reconhecida por muitos norte-americanos como uma obra de um génio, tendo as vendas sido bastante boas durante algum tempo até o negócio acabar por expirar. "A" ainda terá publicado outro livro, Legends, no qual mostra que um país pode ser transformado sem violência, através de uma mudança espiritual. " $\mathrm{A}$ " encontra-se desaparecido numa qualquer prisão da ditadura de Salazar e o jovem poeta americano (Oates ?) procura "salvá-lo" recorrendo a Fernandes. Segundo Giles, Oates, como já foi aventado, distancia-se dos escritores seus contemporâneos:

Throughout her career up to "the Fernandes parables," Oates has consistently attempted "to re-create" and "to sanctify" "a world" by "honoring the complexities" of "the real world"; and the resulting wedding of "mysticism" and "realism" has been a vital ingredient in her artistic power. $(1979,147)$

"A", o eventual mentor ou mestre de Oates, poderá reflectir crenças subconscientes (ou não) da autora, relativamente ao sucesso dos seus livros, ao modo como a América deveria ser transformada politicamente, ou à ideia de escritor "santificador".

No conto, "Plagiarized Material", Oates retrata precisamente um artista atolado no pântano da consciência que, segundo Bender, (418) não "santifica" nem transforma, mas apaga o mundo. Trata-se de um artista constantemente vítima de plágio, antes mesmo de publicar os seus textos, de uma forma dir-se-ia telepática, até que resolve escrever um texto em que refere os seus plagiadores, esperando que tal viesse porventura a intimidá-los, não voltando a ser plagiado, terminando, assim, este conto. Através deste autor português de nome Cabral, como Pedro Álvares Cabral, Oates descreve a produção dos escritores norte-americanos que se encontravam "permanentemente atolados no pântano da consciência": 
All my writing [a escrita de Cabral], as it is written, cancels out the tradition in which it is written. It is not magic, but anti-magic. It has no meaning. It is. It is not even "mine". As you read it, it is not "yours" - and, in fact, as you read it, "you" cease to exist. ${ }^{8}$ I work with words. The words are only themselves; they have no purpose outside themselves. They are hieroglyphics on a page but, unlike hieroglyphics and all crude symbols of man's futile quest for meaning, they hold no meaning; they "are" not even themselves. All my writing is destined to prove that "writing" (and reading) does not exist; writers (and readers) subsequently do not exist.

The world releases a stench; the world is not equal to any subjective, specific, anti-magical assault upon it. That is why my writing reduces the world to words and, ultimately, words to silence. (Oates 1975, 164-165)

Veja-se que se, por um lado, nos poemas dos poetas cépticos o "eu" e o "outro" deixam de importar, por outro lado, Oates, no seu posfácio, revela que não sabe o que é realmente o "eu". É caso para nos interrogarmos se Oates não se aproxima perigosamente de quem se procura demarcar, encontrando-se o foco da diferença entre Oates e os poetas cépticos na recusa do sentido na escrita por parte destes últimos. Para os cépticos tudo na escrita literária se resumirá a jogos de palavras e ao silêncio em termos de sentido, ao passo que para Oates o sentido faz sentido, permitindo que a escrita salve o leitor e salve o mundo, transformando-o. Atente-se, ainda, noutro excerto do mesmo conto, em que um crítico escreve sobre a literatura de Cabral:

is at once Cabral and anti-Cabral, Self and Anti-Self, as his art is both Art and Anti-Art. Cabral refuses to order experience for us; he scorns to 'give a meaning' to life; he scorns life itself, thereby freeing his readers from the centuries-old, tedious, boring sentimentality of the illusion of psychological reality. It is not simply that Cabral so beautifully refuses to lead us into a 'higher morality' (for innumerable modern writers have made this courageous refusal); he cancels out morality itself, he obliterates it by the cerebral perfection of words." (Oates 1975, 166)

8. Aqui não podemos deixar de recordar a afirmação de Oates no posfácio deste livro, já atrás referida: "Repeatedly, one is brought back to the paradox that one can experience the world only though the self - through the mind - but one cannot know, really, what the "self" is". 
Este anti-Eça, segundo o descreve Oates neste conto, compõe um romance com o estilo e a pesada e alegórica moralização de Eça de Queirós (1845-1900), realizado com o poder deste autor português, tornando-se, assim, no próprio mestre de Eça. ${ }^{9}$ Poder-se-á, assim, contestar tanto a opinião de Susana Araújo (65-66) como da crítica Olson Padgett quando defendem que Oates escrevera este livro de contos "with no reverencial or cerimonial gesture at all toward Portuguese literature." (678) De facto, tanto em "Letters from Fernandes from a Young American Poet" como neste último conto tal parece não se verificar. No entanto, poder-se-ia, ainda alegar, com Olson Padgett, que, como aliás o próprio Eça fez com a tradução de As Minas de Salomão de Rider Haggard, Oates valorizou um desconhecido e fraco autor português, Fernandes de Briao, com a tradução de The Poisoned Kiss and Other Stories from the Portuguese: "Oates's possessed authorship of a little bit of literature for Portugal forces us to face the danger of such work rendering Portugal's literature anonymous, of inscribing it only in and by the look of an American other." (681) Acontece que este autor desconhecido poderia ser o próprio Fernando Pessoa que, com esta "valorização", se tornaria anónimo no universo da literatura anglo-saxónica e mundial. Como Susana Araújo sugere, de forma algo ousada, "by using none other than the name Fernandes ('the son of Fernando', Oates hints at a literary genealogy which goes back to Fernando (Pessoa))" $(2010,66)$ A apropriação valorativa de um autor estrangeiro, através da tradução, por uma literatura dominante, como a anglo-saxónica, afigura-se um caso totalmente diferente da apropriação de uma literatura de um sistema central realizada por uma literatura periférica, como a portuguesa. Não se entende como esta obra pode tornar anónima a literatura portuguesa, pois aparentemente essa forma de apropriação parece produzir o efeito contrário, popularizando-o no universo literário anglo-saxónico. Oates terá substituído a sua literatura pela literatura de um país que alega não conhecer e Giles afirma que, na obra desta autora, os cenários

9. Curiosamente, Eça também foi traduzido por Campbell: O Primo Basílio em 1953 e A Cidade e as Serras em 1955. (Monteiro 1998: 22) 
aproximam-se mais de uma alegoria do que de Portugal. (1979, 141) Contudo alegar que Oates substitui a sua literatura por uma literatura de um país que afirma não conhecer parece-nos um pouco forçado, pois Oates, como já foi referido, liberta o seu lado mais recalcado, num exercício de escrita que utilizará Pessoa (e Eça) para marcar a sua posição literária no seio da literatura norte- americana da época. Não substitui, recorre a Pessoa (e a Eça).

Nesta obra, Oates relaciona-se de facto com Portugal? Sim, mas, como já se viu, de forma algo ambígua, sendo que Portugal se torna sobretudo um pretexto para Oates aprofundar a sua própria persona literária, numa altura em que provavelmente a sentiu a entrar em desequilíbrio. No contexto de uma vida intelectual bastante intensa, Portugal constituiu um escape, um país mítico, distante e parado no tempo. Como ela própria reconheceu, Oates não terá tido qualquer interesse pelo país, nunca o tendo sequer visitado. Mas será exactamente assim? O que Oates terá conhecido de Pessoa? Tanto a literatura dos Estados Unidos como a portuguesa beneficiariam com tais esclarecimentos. Portugal corporiza também os problemas dos Estados Unidos de que Oates não quer falar abertamente. A utilização da literatura portuguesa permite a Oates manifestar-se discretamente em relação ao estado do meio literário norte-americano - um livro-manifesto, portanto. A ser verdade, esta apropriação de Pessoa por Oates poderá beneficiar a imagem da literatura portuguesa no mundo, dada a centralidade que a literatura anglo-saxónica assumiu nos dias de hoje. Embora, ao longo deste artigo, não se tenha chegado a conclusões definitivas espera-se que esta reflexão constitua, em si mesma, um contributo para outros desenvolvimentos na área dos Estudos Anglo-Portugueses. 


\section{Obras Citadas}

Araújo, Susana. “Joyce Carol Oates's Transatlantic Personae: Fernando Pessoa and Jorge Luis Borges in the USA". Atlantic Studies.7.1 (2010): 63-78.

Bender, Eilleen T. "Between the Categories: Recent Short Fiction by Joyce Carol Oates". Studies in Short Fiction. 17.4 (1980): 415-423.

Borges, Paulo. "As Coisas são Coisas? Alberto Caeiro e o Zen". Pessoa Plural. 9 (Spring 2016): 107-127.

Caeiro, Alberto. MultiPessoa - Arquivo Pessoa - Obra Aberta.<http://multipessoa.net/labirinto/alberto-caeiro/1>

Camões. Rimas. Ed. Álvaro J. da Costa Pimpão. Coimbra: Almedina, 2005. 20.

Cruz, Mário. “Uma Americana em Lisboa: Mary McCarthy 'Traduz' Portugal (1954)". Journal of Anglo-Portuguese Studies. No 25 (2016): 383-401.

Ferrari, Patrício e Jerónimo Pizarro. "Jorge Luis Borges." Dicionário de Fernando Pessoa e do Modernismo Português. Coordenação de Fernando Cabral Martins. Lisboa: Editorial Caminho, Outubro de 2008. 91-92.

Giles, James R. "Oates' The Poisoned Kiss". Canadian Literature. No 80 (Spring 1979): 138-147.

McCarthy, Mary. "Letter from Portugal". On the Contrary. New York: Farrar, Straus e Cudahy, 1951 (1946). 106-131.

---. "The Vassar Girl" 1933-1974. YouTube: <https://www.youtube.com/watch?$\mathrm{v}=-\mathrm{rIMKDx} 94 \mathrm{OU} \& \mathrm{t}=1006 \mathrm{~s}>$ Acedido em 23-09-2018.

Monteiro, George. The Presence of Pessoa: English, American and Southern African Literary Responses. Kentucky: The University Press of Kentucky, 1998.

---. "Roy Campbell's Delighted Discoveries". Luso-Brazilian Review. University of Wisconsin Press. Vol. 47, N²2 (2010): 135-149.

---. "Imaginary Poets in Real World (an Unpublished Lecture, 1996)". Pessoa Plural, No9 (2016): 298-309.

Moreira, João Paulo. “ 'Um Quarto Alugado. Um Nome Emprestado': Histórias de Portugal, por Fernandes Carol Oates". Comunicação apresentada no VIII Encontro da Associação Portuguesa de Estudos Anglo-Americanos. Coimbra, 1989.

Oates, Joyce Carol/Fernandes. The Poisoned Kiss and Other Stories from the Portuguese. New York: The Vanguard Pres, Inc., 1975 


\section{ESTUDOS / ESSAYS}

---. "The Poisoned Kiss Revealed". Celestial Timepiece, 2010. <https://celestialtimepiece.com/>

---. "The Poisoned Kiss and Other Stories from the Portuguese". Celestial Timepiece, 2015. <https://celestialtimepiece.com/>

Padgett, Jacqueline Olson. "The Portugal of Joyce Carol Oates." Studies in Short Fiction. 31.4 (1994): 675-682.

Pessoa, Fernando. “Thomas Merton's Translations Introduce Portugal's Leading Modern Poet". New York: New Directions, No 19 (1968).

Ricard, Matthieu e Wolf Singer. Cerveau et Méditation: Dialogue entre le Bouddhisme et les Neurosciences. Paris: Allary Éditions, 2017.

Terenas, Gabriela Gândara. "Transatlantic Relationships: Africa, Portugal and the USA in the Early Sixties". Journal of Anglo-Portuguese Studies. No 17 (2008): 287-301. 